\title{
I CONGRESSO BRASILEIRO DE DIREITO ADMINISTRATIVO
}

Sob os auspícios da Universidade Federal do Paraná, Fundação Getúlio Vargas e Departamento Estadual do Serviço Público, réalizou-se em Curitiba, no período de 21 a 25 de fevereiro de 1975, - I Congresso Brasileiro de Direito Administrativo.

O conclave, que contou com a participaŗão de ce ca de seiscentos especialistas de todos os níveis universitários, consitituiu-sa no primeiro encontro nacional no tocante aos estudos de Direito Aúministrativo e questões de pública administraçã̃o.

O Congresso obteve largo êxito, sendo presidente do mesmo - ministro Themistocles Brandão Cavalcanti, do Supremo Tribunal Fe. deral, e presidente da sua Comissão Executiva o professo: Manu ! de Oliveira Franco Sobrinho, catedrático da Universidade Federal cio Paraná.

Foram os seguintes os princípais temas discutidos em plenário e nas comissões:

1 - Conceito do Direito Administrativo Brasileiro.

2 - Problemas Jurídicos da Administração Indireta.

3 - Problemas atuais da desapropriação.

4 - A Justiça Administrativa - problemas e soluções.

5 - Direito Urbanístico.

6 - O servidor público e o regime da CLT.

Participaram dos debates, no primeiro plano, figuras exponenciais do administrativismo brasileiro, como Themistocles B. Cavalcar. ti, Oswaldo Aranha Bandeira de Mello, M. Seabra Fagundes, A. B. Cotrim Neto, Lafaiete Pondé, Paulo Neves de Carva'ho, Ary Florencio Guimarães, Manoel de Oliveira Franco Sobrinho, Hely Lopes Meirelles, Geraldo Ataliba, Celso Antônio Bandeira de Mello, Fernando Andrade de Oliveira, Atamir Quadros Mercês, Sergio Ferraz, e Sérgio de Andréa Ferreira.

Pronunciaram conferências os professores: Marcello Caetano, sobre a "proteção jurisdicional dos administrados"; Caio Tácito, em tor- 
no dos novos problemas expropriatórios; e Celso Antônio de Bandeira Mello, analisando a temática do poder discricionário.

Constituiu ponto alto do certame a criação do Instituto Brasileiro de Direito Administrativo, sendo eleita, no momento, a primeira diretoria executiva com o professor Manoel de Oliveira Franco Sobrinho e Caio Tácito, como presidente e vice-presidente, respectivamente, ficando como secretários os professores Sergio Ferraz, Celso Antônio Bandeira de Mello e Sérgio de Andréa Ferreira.

Na sessão de encerramento, com a presença do professor Theodócio Jorge Atherino, Reitior da Universidade Federal do Paraná, Des. Henrique Nogueira Dorfmund, Presidente do Tribunal de Justiça do Estado e prof. José Munhoz de Mello, Diretor do Setor de Ciências Sociais Aplicadas, concluiram-se os trabalhos com discursos proferidos pelos professores Lafaiette Pondé (Bahia), Ary Florêncio Guimarães (Paraná), Sérgio Ferraz (Rio de Janeiro) e do presidente Manoel de Oliveira Franco Sobrinho. 